\title{
The Role of Diffusion Weighted MRI in The Assessment of Post Ablation HCC Viability
}

\author{
Hamed A. Morsi , Medhat M. Refaat, Osama T. Galal
}

\begin{abstract}
Department of Radiology, faculty of medicine, Banha university, Banha Egypt
\end{abstract}

Correspondence to: Hamed A. Morsi, Department of Radiology, faculty of medicine, Banha university, Egypt

Email:

dr.masrry@gmail.com

Received: 22 July 2019

Accepted: 22 September 2019

\section{Abstract:}

Background: Hepatocellular carcinoma (HCC) is the most common primary liver malignancy. Local ablative therapies include chemical (ethanol, acetic acid) or thermal ablation [radiofrequency ablation (RFA), microwave, laser, cryoablation] are curative treatment options that treat HCC. The apparent diffusion coefficient (ADC) calculated in diffusion-weighted MRI has become a favorable biomarker of tumor. The ADC is a measure of the mobility of water in tissues Methods: 30 cases of patients having $\mathrm{HCC}$ to radiology department of Damietta Cancer Center who underwent locoregional therapies (radio frequency ablation, microwave ablation percutaneous ethanol injection and trans-arterial hepatic chemoembolization) over a period of 18 months (APR.2017-OCT.2018). Patient are scheduled for dynamic contrast enhanced (DCE) MRI and diffusion weighted images (DWI) either in the routine follow up or after inconclusive triphasic CT study to assess tumor response to treatment and detect residual or recurrent lesions. Results: The ADC variable was found to be a fair indicator to differentiate marginal recurrence of $\mathrm{HCC}$ from benign or pseudo- lesions the sensitivity of DWI was $80 \%$, its Specificity was $76.7 \%$, positive predictive value was $53.3 \%$ and negative predictive value was $92 \%$. Conclusion: we concluded that DWI together with conventional imaging is a promising tool in the evaluation of $\mathrm{HCC}$ post ablation. DWI can provide information about molecular tissue characteristics; it can help to distinguish between viable and necrotic tumor areas thus facilitating the diagnosis of residual or recurrent tumor. We could recommend a cut -off value $1.024 \times 10$ $3 \mathrm{~mm}^{2} / \mathrm{sec}$, with $\mathrm{t}$ values below this level, express viability of the malignancy.

Key words: ADC, Ablation, HCC, Viability 


\section{Introduction:}

Hepatocellular carcinoma (HCC) is the most common primary liver malignancy, (1). Local ablative therapies include chemical (ethanol, acetic acid) or thermal ablation [radiofrequency ablation (RFA), microwave, laser, cryoablation] are curative treatment options treat HCC (2).

The ultimate goal of locoregional therapy of HCC is tumor cell death and necrosis (3). Imaging evaluation of HCC after therapy is of paramount importance (4).

Traditional anatomical response criteria are solely based on tumor size changes (5). Simple evaluation of morphological alterations may not be ideal since relevant size changes for response assessment usually take time to $\operatorname{occur}(6)$.

The post-therapy contrast enhancement changes are not unique features of tumorous lesions and may also occur in benign posttreatment changes. (7). To overcome these shortcomings, technological advancements in functional MR imaging, such as diffusionweighted imaging (DWI), are increasingly being used and evaluated for both posttreatment response assessment and outcome prediction prior to therapy (8).

The apparent diffusion coefficient (ADC) calculated in diffusion-weighted MRI has become a favorable and promising biomarker of tumor response to therapy. The ADC is a measure of the mobility of water in tissues. Viable tumors are high in cellularity, and the cells have an intact cell membrane that restricts the mobility of water molecules and causing a relatively low ADC. Conversely, cellular necrosis increases membrane permeability, allowing water molecules to move freely and causing a relative increase in $\operatorname{ADC}(9)$.

The aim of this study was to evaluate the role of functional MRI with Diffusion Weighted technique in the assessment of hepatocellular carcinoma (HCC) viability after ablation.

\section{Patients and Methods}

This prospective study was carried on 30 cases of patients having HCC referred to radiology department of Damietta Cancer Center from outpatient clinic of medical and surgical oncology departments who underwent locoregional therapies (radio frequency ablation, microwave ablation percutaneous ethanol injection and trans arterial hepatic chemoembolization) over a period of 18 months (April, 2017-October, 2018). The patients' age ranged between 20 to 75 years, 22 patients were males and 8 were females, all patients had liver cirrhosis related to chronic 
viral hepatitis. All procedures are approved by ethical committee of Damietta cancer center.

\section{Inclusion Criteria:}

- Patients with HCC who underwent, RFA, MWA, PEI \&TACE.

- Prior informed consent

- At least one measurable lesion.

\section{Exclusion Criteria:}

- Life expectancy $<6$ months.

- Contraindications to contrast media, e.g. patients with renal failure,

- Patients allergic to contrast media.

- Contraindications to magnetic resonance imaging, e.g. claustrophobia,

- Patients having cardiac prosthesis, metallic plates....etc

- Other tumors other than hepatocellular carcinoma.

All patients underwent locoregional ablation therapy scheduled for dynamic contrast enhanced (DCE) MRI and diffusion weighted images (DWI) either in the routine follow up or after inconclusive triphasic $\mathrm{Ct}$ study to assess tumor response to treatment and detect residual or recurrent lesions.

All cases were viewed by 2 experienced radiologists in hepatic imaging

MR images were analyzed for the following:

- The morphological features of each lesion were recorded including size, border, signal characteristics at $\mathrm{T} 1$ and $\mathrm{T} 2$ signal characteristics.

- Pattern of enhancement in the dynamic imaging.

- Signal intensity on diffusion images with ADC values using a commercially windows workstation.

The region of interest (ROI) used to measure the ADC value is applied as following:

- The ROI included nearly the entire lesion if it displayed diffuse homogeneous or heterogeneous signal on ADC map.

- If the lesion shows well defined areas of restriction and other areas of facilitation the ROI is placed on each area separately and two ADC values are calculated.

- The ADC values were measured three times and the average was taken.

Data were tabulated, coded then analyzed using the computer program SPSS version 23.0 (Chicago, Ill, USA)

\section{Results:}

All DWI images using different $\mathrm{p}$ values, $\mathrm{ADC}$ maps and $\mathrm{ADC}$ values were interpreted and classified eventually into two groups: -

1- Diffusion Free lesions were considered when hypo-intense signals in diffusion weighted images are noted or concomitant hyper-intense signals in diffusion weighted images with hyper-intense signals in ADC maps (shine through effect) is noted. 
2- Diffusion restricted lesions were considered when hyper-intense signals in diffusion weighted images are noted simultaneously with hypo-intense signals in ADC maps.

- Out of the 40 locally treated lesions lesions showed free diffusion (62\%) while (15) lesions showed restricted diffusion (38\%) .

The lesion margin and perilesional area on DWI:

The margins of all lesions showed free diffusion while the perilesional area showed restricted diffusion in one lesion and free diffusion

Quantitive analysis of ADC Values: -

- The highest intralesional ADC values RANGED FROM .677: 1.663.

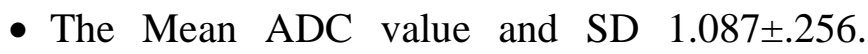
(table 8)

- The ADC values among the diffusion free lesions ranged from 1.040: 1.663 while the ADC values among the diffusion restricted lesions ranged from .667: 1.008

- The mean ADC values among the diffusion free lesions $(1.131 \times 10-3 \mathrm{~mm} 2 / \mathrm{sec})$ while the mean ADC values among the diffusion restricted lesions $\left(.957 \times 10-3 \mathrm{~mm}^{2} / \mathrm{sec}\right)$

Analysis of Dynamic MRI diagnostic criteria According to the pattern of enhancement characteristic for HCC, lesions are sorted into either enhancing or non-enhancing groups.

1- Enhancing group: - include lesions which showed arterial enhancement and washout in the portal and delayed phases.
2- Non-enhancing group: - include lesions which showed no intra lesion enhancement pattern of HCC or showed reactive marginal and surrounding area persistent enhancement yet no washout.

Out of the 40 locally treated lesions (30) lesions showed no intralesional enhancement $(75 \%)$ while (10) lesions showed intralesional enhancement (25\%).

\section{Marginal assessment: -}

The margin of the locally treated lesions showed no enhancement in 6 lesions $(15 \%)$ and persistent enhancement in 34 lesions $(85 \%)$.

\section{Perilesional area assessment: -}

The perilesional area of the locally treated lesions showed no enhancement in 30 lesions (75\%) and persistent enhancement in 10 lesions $(25 \%)$.

\section{$\underline{\text { Final total indices }}$}

Upon correlating the diffusion findings to the final diagnoses, among the (30) ablated lesions (23) lesions showed free diffusions $(76.7 \%)$ and (7) lesions showed restricted diffusion (23.3\%) while among the (10) residual lesions (8) showed restricted diffusion $(80 \%)$ and (2) lesions showed free diffusion $(20 \%)$ 
Table (1) Number and frequency of enhancement pattern of the lesions:-

\begin{tabular}{llcc}
\hline & & No & \% \\
\hline \multirow{4}{*}{ Main lesion } & ENHANCEMENT & 10 & $25.0 \%$ \\
& $\begin{array}{l}\text { PERSISTENT } \\
\text { ENHANCEMENT }\end{array}$ & 2 & $5.0 \%$ \\
Margin & NO ENHANCEMENT & 6 & $15.0 \%$ \\
& PERSISTENT & 34 & $85.0 \%$ \\
surrounding & ENHANCEMENT & & \\
area & NO ENHANCEMENT & 30 & $75.0 \%$ \\
& PERSISTENT & 10 & $25.0 \%$ \\
\hline & ENHANCEMENT & & \\
\hline
\end{tabular}

Table (2) DWI-MRI \& Dynamic MRI results

\begin{tabular}{llcc}
\hline & & No & \% \\
\hline \multirow{2}{*}{ Dynamic } & Ablated & 30 & $75.0 \%$ \\
& Residual & 10 & $25.0 \%$ \\
\multirow{2}{*}{ DWI } & Free & 25 & $62.5 \%$ \\
& Restricted & 15 & $37.5 \%$ \\
\hline
\end{tabular}

Table (3): Correlation of the DWI results to in dynamic MRI results.

\begin{tabular}{llrrrrr}
\hline & & \multicolumn{4}{c}{ Dynamic } & P \\
& & \multicolumn{2}{c}{ Ablated } & \multicolumn{2}{c}{ Residual } & \\
& & No & \% & No & \% & \\
\hline \multirow{2}{*}{ DW } & Free & 23 & $76.7 \%$ & 2 & $20.0 \%$ & $<0.001^{*}$ \\
I & Restricte & 7 & $23.3 \%$ & 8 & $80.0 \%$ & \\
& d & & & & & \\
\hline
\end{tabular}

Table (4):- According to DWI, false and true positive lesions \& false and true lesions

\begin{tabular}{ccc}
\hline & No \\
\hline DWI & True Positive & 8 \\
False negative & 2 \\
True negative & 23 \\
False Positive & 7 \\
\hline
\end{tabular}

Table (5): shows the different indices of the DWI

\begin{tabular}{ll}
\hline Sensitivity & $80.0 \%$ \\
Specificity & $76.7 \%$ \\
PPV & $53.3 \%$ \\
NPV & $92.0 \%$ \\
Accuracy & $77.5 \%$ \\
\hline
\end{tabular}

PPV: Positive predictive value NPV: negative predictive value
Qualitative analysis of the ADC value:-

The different ADC values elicited from the corresponding ADC maps were calculated. The difference between ADC variables among the malignant and benign groups were statistically significant, $p$ value 0.03 . The ROC curve obtained by plot at different cut off values is shown in Figure. The best cut off that maximizes sensitivity and specificity is $1.024 \times 10-3 \mathrm{~mm}^{2} / \mathrm{sec}$. At this ADC value, the sensitivity is $80 \%$ and specificity is $76.7 \%$. A statistical software showed that the $\mathrm{AUC}=0.73$ with $95 \%$ CI from 0.540 to 0.920 . It seems from the ROC that ADC variable is a fair indicator to detect residual of $\mathrm{HCC}$ after ablation. (Area under the curve:- excellent 0.9-1, good 0.8-0.9, fair 0.7-.8, poor 0.6-0.7, fail $0.5-0$.

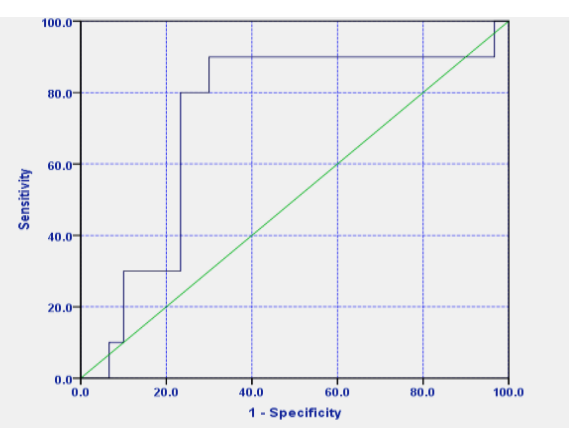

Figure (1):- Results of receiver operating curves for ADC values in distinguishing viable and non-viable groups

Table (6): The different indices of the ADC

\begin{tabular}{lc}
\hline AUC(95\% CI) & $0.73(0.54-0.92)$ \\
p value & $0.03 *$ \\
Cutoff value & $<1.024$ \\
Sensitivity & $80.0 \%$ \\
Specificity & $76.7 \%$ \\
PPV & $53.3 \%$ \\
NPV & $92.0 \%$ \\
Accuracy & $\mathbf{7 7 . 5 \%}$ \\
\hline
\end{tabular}


Table (7):- According to ADC, false and true positive lesions \& false and true lesions

\begin{tabular}{ccc}
\hline & No \\
\hline ADC & True Positive & 8 \\
& False negative & 2 \\
True negative & 23 \\
False Positive & 7 \\
\hline
\end{tabular}

Case No.1 (Fig.2):

- Clinical history: A 70 years old female with hepatocellular carcinoma (HCC) was candidate for microwave ablation.
- MRI six months After Microwave ablation:

- Pre-contrast T1WI: isointense lesion with surrounding hypointense rim (Fig.2 a).

- Pre-contrast T2WI: the lesion is hyperintense (Fig.2 b).

- Final conclusion: Successfully ablated lesion showing free diffusion and high ADC values.

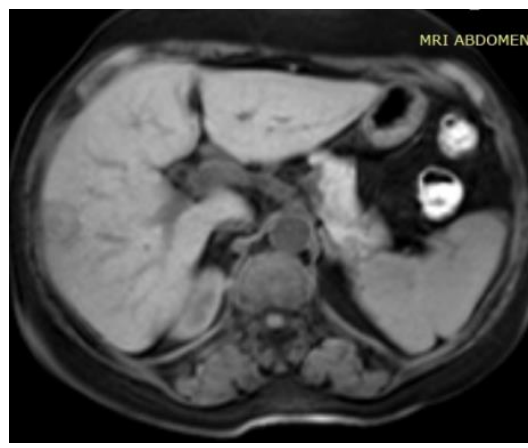

(2a) T1

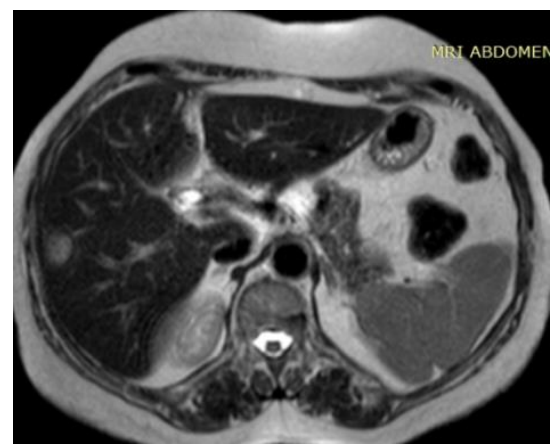

(2b) T2

DWI: the lesion is hyperintense (Fig. 2 c, d \& e).

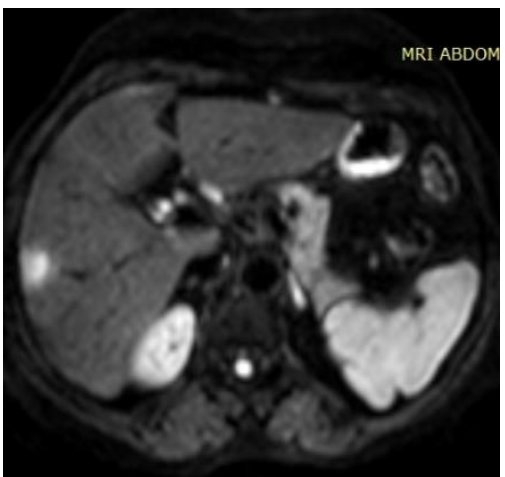

(2C) DWI

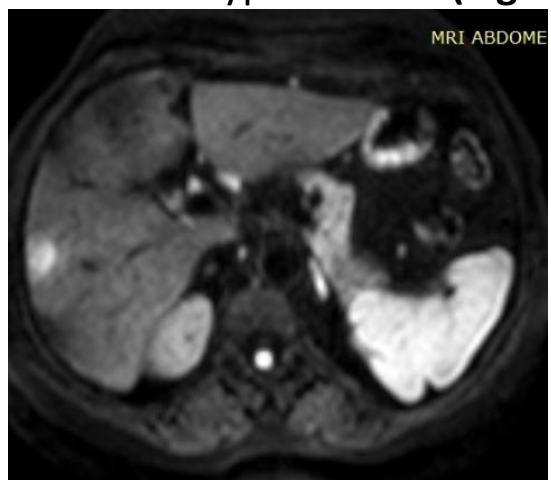

(2d) DWI

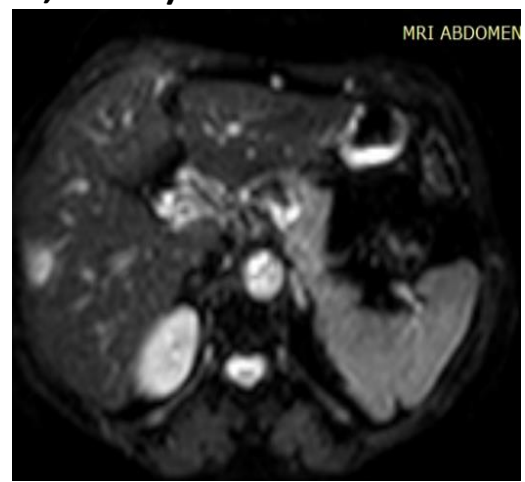

(2e) DWI

ADC map: The lesion is hyperintense to liver parenchyma.

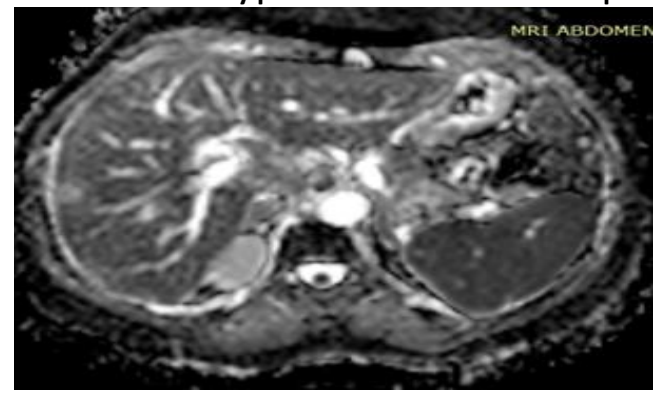

(2f) ADC 


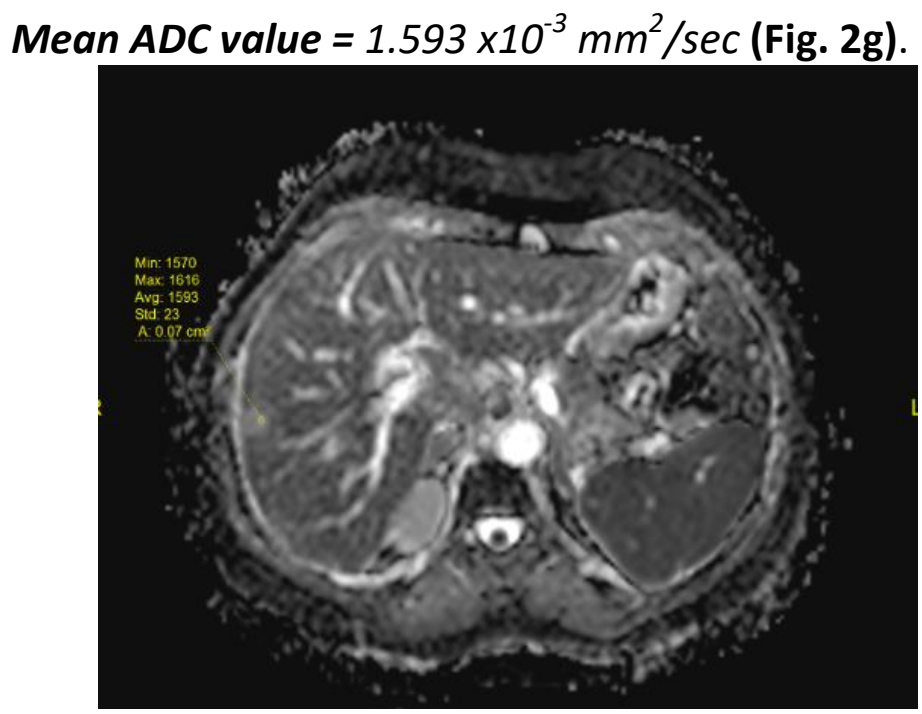

(2g) ADC value

Dynamic MRI: The lesion show no enhancement (Fig.2 h, I \& j).

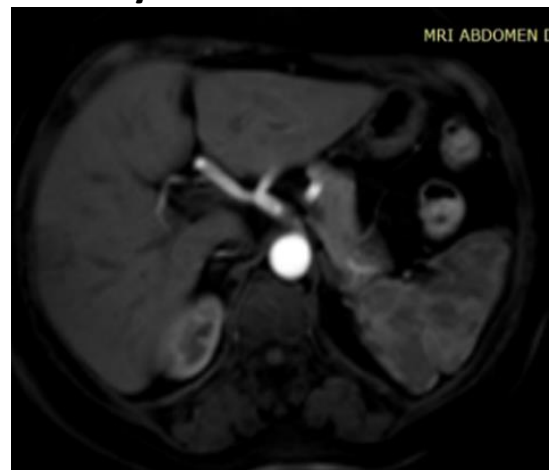

(2h) dynamic arte

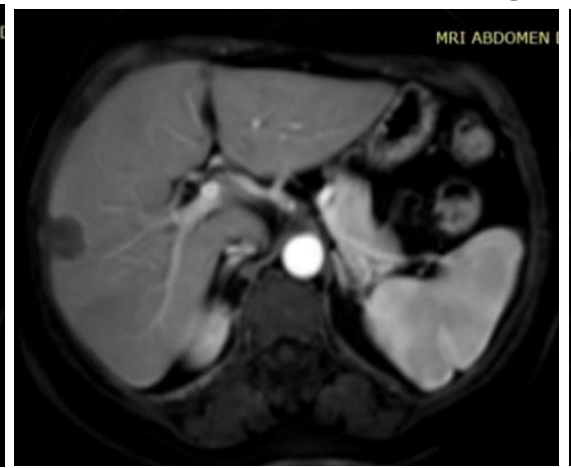

(2i) dynamic venous

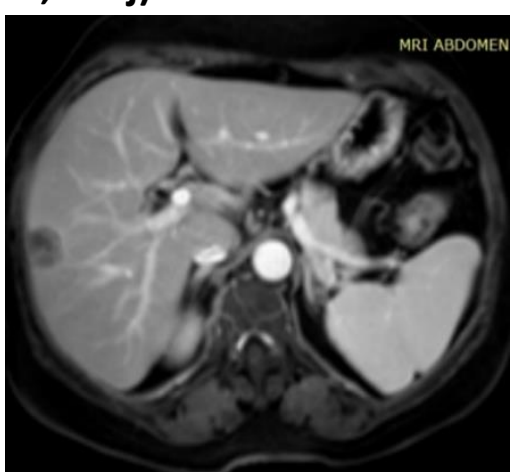

(2j) dynamic delayed

\section{Case No.2 (Fig.3):}

- Clinical history: A 46 years old male with hepatocellular carcinoma (HCC) was candidate for radiofrequency ablation.

- MRI one month After radiofrequency ablation (Fig. 3):

- Pre-contrast T1WI: hypointense lesion at seg VI (Fig. 3a).

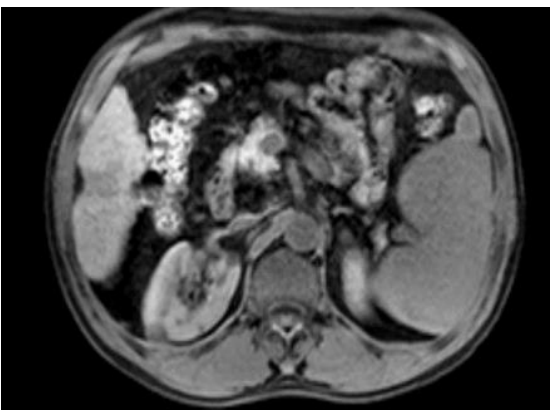

T1 (Fig.3 a1)
- Pre-contrast T2WI: The lesion is hyperintense (Fig. 3b).

- Final conclusion: residual lesion showing restricted diffusion and low $\mathrm{ADC}$ values (true +ve).

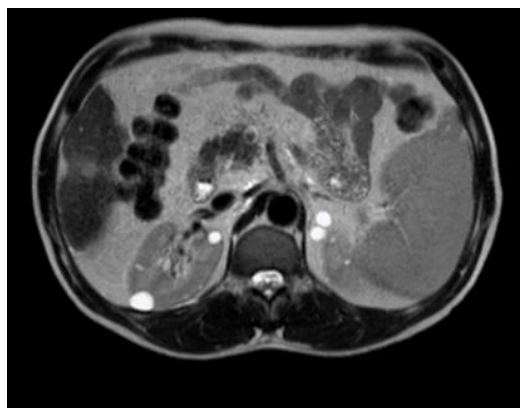

T2 (Fig.3 b) 
DWI: the lesion is hyperintense at different b values (Fig. 3 c,d\&e).

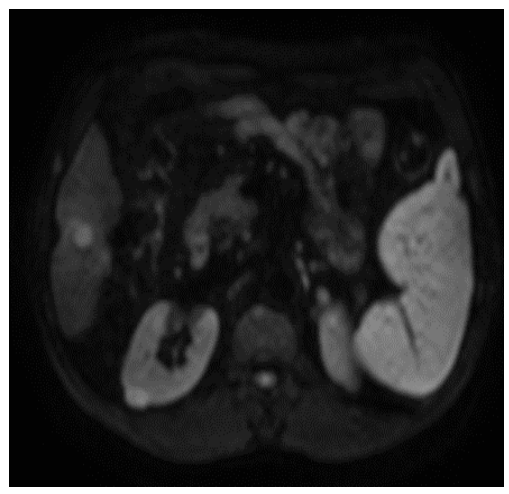

(Fig.3 c)

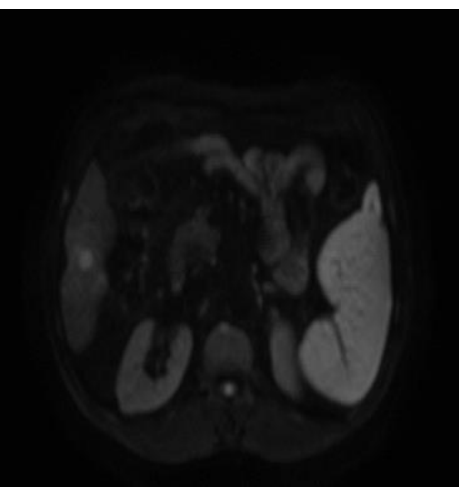

(Fig.3 d).

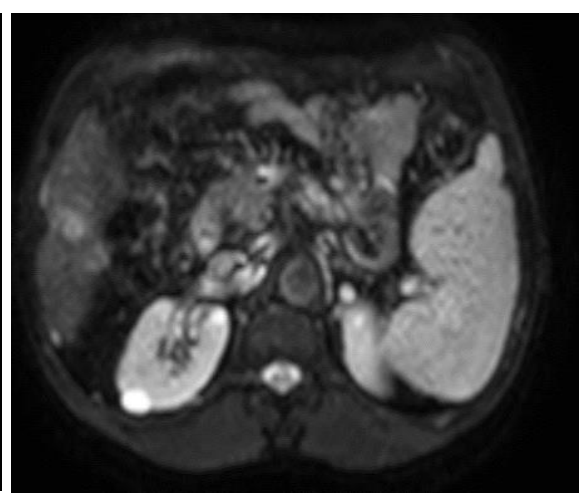

(Fig.3 e).

ADC map: The lesion is hypointense to liver parenchyma (Fig.3 f1\&f2).

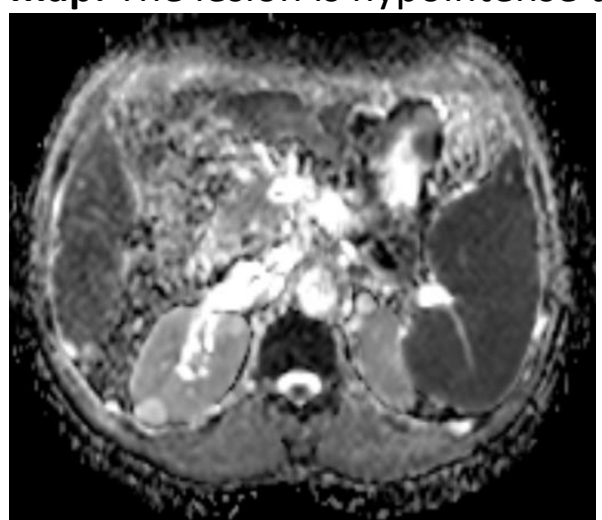

(Fig.3 f1)

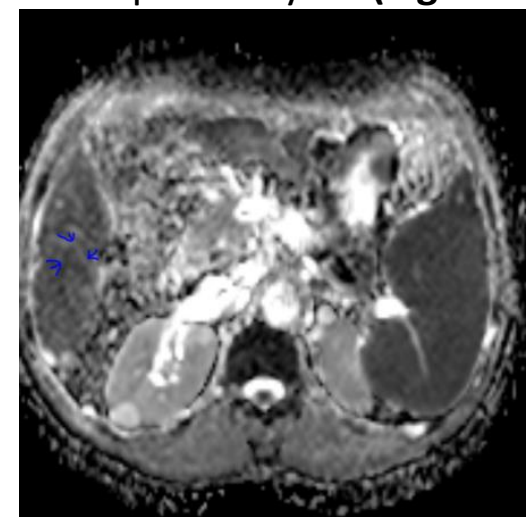

(Fig.3 f2)

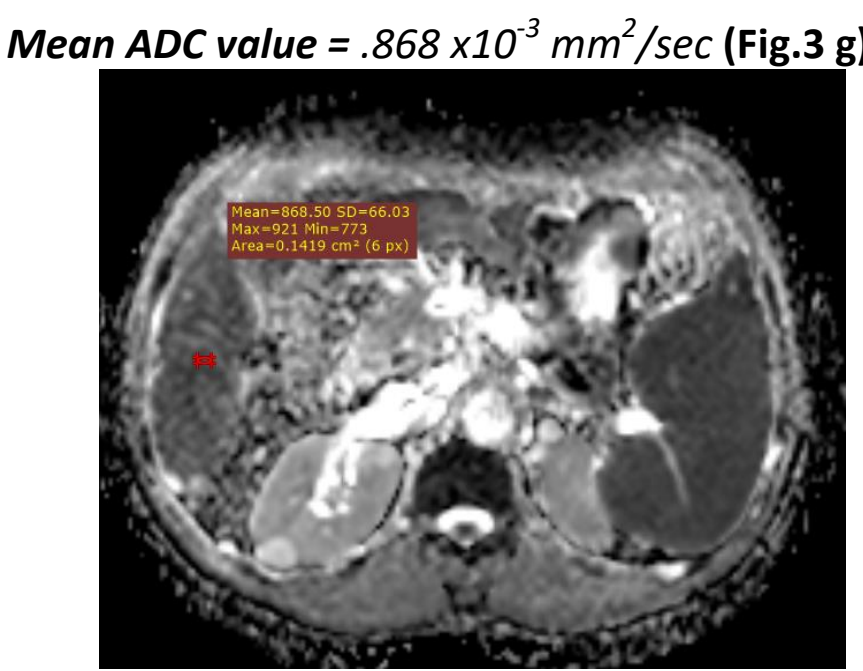

(Fig.3 g) 
Dynamic MRI: the lesion show arterial enhancement with portal and delayed washout (Fig.3 h, I \& j).

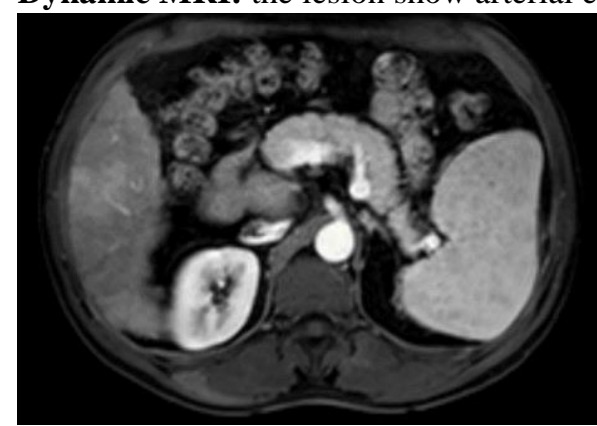

Arterial (Fig.3 h)

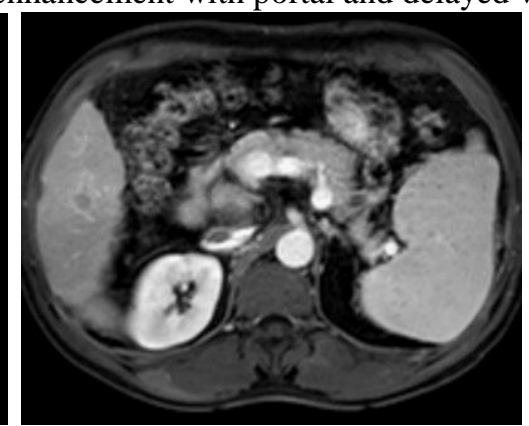

Portal (Fig.3 i)

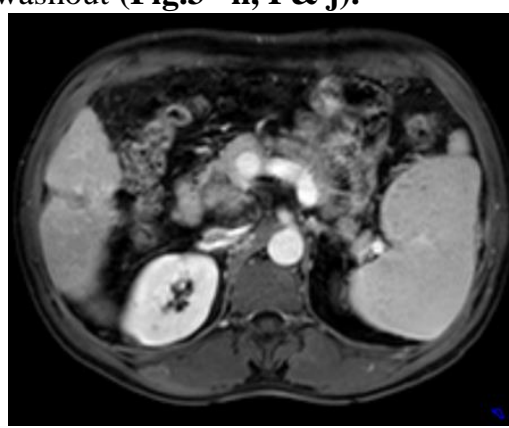

Delayed (Fig.3 j)

\section{Discussion:}

Hepatocellular carcinoma (HCC) is the most common primary malignancy of the liver. It claims more than 500,000 lives annually and is the third leading cause of cancer deaths worldwide. Most of the patients who are not fit for resection/transplantation undergo less invasive

Functional MRI techniques such as Diffusionweighted imaging (DWI), detects early MR signal changes in tissues within several weeks of treatment, based on the degree of cell membrane integrity (10).

The aim of the present study was to compare functional DWI MRI to contrast enhanced MRI to determine the usefulness of diffusion weighted imaging in detection of residual viable tumor tissue in hepatocellular carcinoma after locoregional treatment.

It has been shown that respiratory triggered DW MR imaging improves lesion detection, compared with breath-hold DW MR imaging (sensitivity for lesion detection, $93.7 \%$ vs $84.3 \%$ ) (11) and improves image quality, SNR, and ADC quantification (12).

In our study, we used respiratory-triggered DW to increase the SNR and CNR without compromising the ADC measurements. In this study the breath-hold DW MR imaging technique was used. (13)

In our work 30 patients displayed $40 \mathrm{HCC}$ lesions. ten lesions displayed residual tumor tissue and (30) lesions appeared free of residual tumor tissue. The sensitivity of DWI was $80 \%$, its specificity was $76.7 \%$, positive predictive value was $53.3 \%$ and negative predictive value was $92 \%$.

Different studies worldwide were established to determine the value of DW-MRI in evaluation of treatment response after loco regional therapies.

In the study done in 2017, DWI had a sensitivity of $82 \%$, a specificity of $73.9 \%$, 
PPV value of $70 \%$, NPV of $85 \%$ and an overall agreement of $77.5 \%$. (14)

In ElSaid et al. (13) study of DWI, reader 1 evaluation yielded a sensitivity of $70.59 \%$, and a specificity of $75 \%$, a positive predictive value of $82.76 \%$ and a negative predictive value of $60 \%$ and $95 \%$ confidence interval of (64-94\%) compared to, $76.47 \%, 90 \%, 92.86 \%$ and $69.23 \%$ and (76-99\%) respectively in reader 2 .

In a study on the qualitative DWI findings showed sensitivity of $83.9 \%$, specificity of $64.3 \%$, positive predictive value of $72.2 \%$, and negative predictive value of $78.3 \%$ and overall accuracy of $74.5 \%$. (15)

Data on DWI for response assessment can still be highly heterogeneous, most likely due to differing study protocols and MR hard- and software used (16).

On combination DWI and Gd-MRI, it was stated that DWI increased the sensitivity compared to Gd-MRI alone (92\% vs. $85 \%$; p $=0.125)$ only to a non-significant degree while specificity decreased from $65 \%$ to $50 \%$. Therefore, DWI is only of little to no value for recurrence detection according to this literature.(17)

So, in our study we postulated that the false positive cases are likely originating from liquefactive necrosis or intralesional hemorrhage (hyperintense on T1WIs) that causes diffusion restriction.

In our study we used quantitative ADC calculation of the treated lesions which is dependent on multiple pre chosen $b$ values.

In our DWI study, b values were $(0,20,400$, $800 \mathrm{sec} / \mathrm{mm}^{2}$ ), with the application of parallel imaging and breath triggering technique, a satisfying image quality has been achievable on a 1.5-T scanner within an acceptable acquisition time.

In another study done in 2017, p values of 50,400 and $800 \mathrm{sec} / \mathrm{mm}^{2}$ to avoid intravoxel perfusion effect which result from low $p$ values (less than 50) in addition high p value with its higher accuracy in lesion characterization, was used.(14)

In our study, the difference between ADC variables between the malignant and benign groups was statistically significant $\mathrm{P}$ value 0.001 and the area under the curve 0.73 . The best cut off that maximizes sensitivity and specificity is $1.024 \times 10^{-3}$. At this ADC value, the sensitivity is $80 \%$ and specificity is $76.7 \%$.

We found from the ROC that ADC variable is a fair indicator to differentiate marginal recurrence of HCC from perilesional pseudoor benign lesions. 
It was stated that quantitative measurements of diffusion showed that malignant lesions present lower ADC values than benign ones and surrounding liver parenchyma.(18)

In a study done on 2016, the measured cutoff value between the completely ablated lesions and residual/recurrent lesions was $1.05 \times 10^{-3} \mathrm{~mm}^{2} / \mathrm{s}$. and showed that ablated zones can be differentiated from liver parenchyma visually in the DW-MRI and by means of ADC in all patients. There is no statistical difference in the mean ADC values between the ablated zones of the resolved $1.37 \times 10^{-3} \mathrm{~mm} 2 / \mathrm{s}$ and unresolved lesions $1.39 \times 10^{-3} \mathrm{~mm}^{2} / \mathrm{s}$ (p value 0.7$)$. (19)

It was stated that the difference between the malignant residual and well ablated groups' ADC variables was statistically significant $P$ value 0.009 . (14)

In a study done on 2017, the measured ADC values showed significant difference $(\mathrm{P}$ value $<0.05$ ) between the ADC values measured in the active tumoral areas and necrotic areas. ROC analysis for ADC values showed area under curve 0.7 and maximum combined sensitivity and specificity of $79 \%$ and $69.6 \%$ respectively at cutoff ADC value of $1.395 \mathrm{~mm}^{2} / \mathrm{sec}$. (15)

In another study, there was no statistical difference in the mean ADC values between the entire ablation zones of the resolved and unresolved groups ( $\mathrm{p}$ value 0.70).(20)

Completely treated lesions showed significant rising changes regarding $\mathrm{ADC}$ values after $\mathrm{RF}$ ablation and no residual enhancement was detected on subtraction images. viable tumoral tissue appeared hyperintense with significantly lower ADC values $\left(0.8 \times 10^{-3}\right.$ $\mathrm{mm}^{2} / \mathrm{sec}$ ) than completely ablated necrotic tissue which appeared hypointense with higher ADC values $(1.4 \times 10-3 \mathrm{~mm} 2 / \mathrm{sec})$, The mean ADC of the well ablated lesion was 1.4 $\mathrm{X} 10^{-3} \mathrm{~mm}^{2} / \mathrm{sec}$ and of the residual lesion 0.8 X $10^{-3} \mathrm{~mm}^{2} / \mathrm{sec}$ with significant statistical difference between the residual viable tumor and the well ablated lesions, Moreover, it was recommend a cut-off value of $1.233 \times 10^{-3} \mathrm{~mm}^{2} / \mathrm{s}$. The values below this level, express viability of the malignancy.

It was not possible to calculate an ADC cut off value from the ROC curve because the AUC was insignificant and false-negative identification of necrotic tissue may result from well-differentiated HCC. (13)

In a study done in 2014 , it was concluded that, viable and necrotic tumor tissues may occasionally be difficult to characterize with the visual assessment of the DW-MRI alone (22). Yet, we could still calculate a post treatment average for good and poor responding lesions. 
In ElSaid et al. (13) study, the mean ADC value for necrotic lesions was 1.16 and $1.24 \times 10^{-3} \mathrm{~mm}^{2} / \mathrm{sec}$ as detected by reader 1 and 2 respectively. The mean ADC for residual disease was 1.07 and $1.05 \times 10^{-3}$ $\mathrm{mm}^{2} / \mathrm{sec}$ as detected by both readers respectively.

In 2012, it was found that viable lesions values were $0.97 \pm 0.39 \times 10^{-3} \mathrm{~mm}^{2} / \mathrm{sec}$ and non- viable lesions were $1.18 \pm 0.34 \times 10^{-3}$ $\mathrm{mm}^{2} / \mathrm{sec}(\mathrm{p}=0.002)(23)$

In 2009, Mannelli and co-workers concluded that ADC had a weaker correlation with histopathologic degree of tumor necrosis compared to contrast- enhanced subtraction MRI image. However, there was no difference between the two methods in the diagnosis of complete tumor necrosis. On the bases of their study, they believe that DWI can be used as an alternative to contrast- enhanced MRI in the care of patients who cannot administrate gadolinium contrast material, such as patients with renal insufficiency. (24)

In another study done in 2011, it was concluded that ADC value may be a useful tool in the assessment of HCC response, but it may not be sensitive to tumor recurrence as compared with DCE MR imaging. (25)

As stated in 2014, DWI can quantify HCC tumor necrosis, and the ADC value may be useful to determine necrotic and viable tumor tissues. Additionally, DW-MRI improved liver lesion detection. Therefore, DWI may be an option for the short-term follow-up of HCC patients following chemoembolization and may guide patient management for reducing radiation exposure of $\mathrm{CT}$ examination and the risk of contrast materialinduced nephropathy. (22)

Gluskin and co-workers stated that the main strengths of diffusion MRI images are to increase the confidence in diagnosis of HCC especially when intravenous contrast administration is not possible or for small lesions adjacent to vessels.

\section{References:}

1. FORNER, A., REIG, M., VARELA, M., BURREL, M., FELIU, J., BRICEÑO, J., et al: 2016. Diagnosis and treatment of hepatocellular carcinoma. Update consensus document from the AEEH, SEOM, SERAM, SERVEI and SETH. Medicina Clínica (English Edition), 146, 511. e1511. e22.

2. CHO, Y. K., KIM, J. K., KIM, M. Y., RHIM, H. \& HAN, J. K. 2009. Systematic review of randomized trials for hepatocellular carcinoma treated with percutaneous ablation therapies. Hepatology, 49, 453-459.

3. RYAN, M. J., WILLATT, J., MAJDALANY, B. S., KIELAR, A. Z., CHONG, S., RUMA, J. A. \& PANDYA, A. 2016. Ablation techniques for primary and metastatic liver tumors. World journal of hepatology, 8, 191. 
4. MEMON, K., KULIK, L., LEWANDOWSKI, R. J., WANG, E., RIAZ, A., RYU, R. K., et al.: 2011. Radiographic response to locoregional therapy in hepatocellular carcinoma predicts patient survival times. Gastroenterology, 141, 526-535. e2.

5. ARORA, A. \& KUMAR, A.: 2014. Treatment response evaluation and follow-up in hepatocellular carcinoma. Journal of clinical and experimental hepatology, 4, S126-S129.

6. VINCENZI, B., DI MAIO, M., SILlETTA, M., D'ONOFRIO, L., SPOTO, C., PICCIRILlO, M. C., et al.: 2015. Prognostic relevance of objective response according to EASL criteria and mRECIST criteria in hepatocellular carcinoma patients treated with loco-regional therapies: a literature-based meta-analysis. PLoS One, 10, e0133488.

7. IBRAHIM, S. M., NIKOLAIDIS, P., MILLER, F. H., LEWANDOWSKI, R. J., RYU, R. K., SATO, K. T., SENTHILNATHAN, S., RIAZ, A., KULIK, L. \& MULCAHY, M. F. 2009. Radiologic findings following Y90 radioembolization for primary liver malignancies. Abdominal imaging, 34, 566-581.

8. JIANG, T., ZHU, A. X. \& SAHANI, D. V. 2013. Established and novel imaging biomarkers for assessing response to therapy in hepatocellular carcinoma. Journal of hepatology, 58, 169-177.

9. BUIJS, M., VOSSEN, J. A., HONG, K., GEORGIADES, C. S., GESCHWIND, J.-F. H. \& KAMEL, I. R. 2008. Chemoembolization of hepatic metastases from ocular melanoma: assessment of response with contrast-enhanced and diffusionweighted MRI. American Journal of Roentgenology, 191, 285-289.

10. YUAN, Z., YE, X. D., DONG, S., XU, L. C., XU, X. Y., LIU, S. Y. \& XIAO, X. S. 2010. Role of magnetic resonance diffusion-weighted imaging in evaluating response after chemoembolization of hepatocellular carcinoma. Eur J Radiol, 75, e9-14.

11. PARIKH, T., DREW, S. J., LEE, V. S., WONG, S., HECHT, E. M., BABB, J. S. \& TAOULI, B. J. R. 2008. Focal liver lesion detection and characterization with diffusion-weighted MR imaging: comparison with standard breath-hold T2weighted imaging. 246, 812-822.

12. TAOULI, B. \& KOH, D.-M. J. R. 2009. Diffusionweighted MR imaging of the liver. 254, 47-66.

13.ELSAID, N. A. E., KADDAH, R. O., FATTAH, M. S. A. \& SALAMA, N. M. 2016. Subtraction MRI versus diffusion weighted imaging: Which is more accurate in assessment of hepatocellular carcinoma after Trans Arterial Chemoembolization (TACE)? The Egyptian Journal of Radiology and Nuclear Medicine, 47, 1251-1264.

14.EBRAHEEM EBEED, A., ABD EL-HAMIED ROMEIH, M., MOHAMED REFAT, M. \& HAMDY YOSSEF, M. 2017. Role of dynamic contrast-enhanced and diffusion weighted MRI in evaluation of hepatocellular carcinoma after chemoembolization. The Egyptian Journal of Radiology and Nuclear Medicine, 48, 807-815.

15. YOUSEF, M. I., REFAAT, M. M. \& FAHEEM, M. H. 2017. Role of diffusion-weighted magnetic resonance imaging in the evaluation of hepatocellular carcinoma response to transcatheter arterial chemoembolization using drug eluting beads; correlation with dynamic MRI. The Egyptian Journal of Radiology and Nuclear Medicine, 48, 817-824.

16.LUDWIG, J., CAMACHO, J., KOKABI, N., XING, M. \& S KIM, H. 2015. The Role of Diffusion-Weighted Imaging (DWI) in Locoregional Therapy Outcome Prediction and 
Response Assessment for Hepatocellular Carcinoma (HCC): The New Era of Functional Imaging Biomarkers.

17. YU, J. S., KIM, J. H., CHUNG, J. J. \& KIM, K. W. 2009. Added value of diffusion-weighted imaging in the MRI assessment of perilesional tumor recurrence after chemoembolization of hepatocellular carcinomas. J Magn Reson Imaging, 30, 153-60.

18.SZUROWSKA, E., NOWICKI, T. K., IZYCKASWIESZEWSKA, E., ZADROZNY, D., MARKIET, K. \& STUDNIAREK, M. 2013. Predictive value of apparent diffusion coefficient in evaluation of colorectal carcinoma hepatic metastases' response to radiofrequency ablation. 38, 1027-1032.

19. MOSTAFA, M. M. S. 2016. Diffusion weighted and dynamic contrast enhanced magnetic resonance imaging in assessment of malignant liver tumors after percutaneous radiofrequency ablation. The Egyptian Journal of Radiology and Nuclear Medicine, 47, 1195-1205.

20.MAHMOUD, B. E. M. H., ELKHOLY, S. F., NABEEL, M. M., ABDELAZIZ, A. O., ELBAZ, T., SHOUSHA, H. I., IBRAHIM, M., HASHEM, A., et al 2016. Role of MRI in the assessment of treatment response after radiofrequency and microwave ablation therapy for hepatocellular carcinoma. The Egyptian Journal of Radiology and Nuclear Medicine, 47, 377-385.

21. MOHAMED, A. M., LOUKA, A. L. \& GHAZEE, A. F. J. E. J. O. H. M. 2017. The Role of Diffusion Weighted MR Imaging in Assessment of
Hepatocellular Carcinoma After Radiofrequency Ablation. 68.

22. YUAN, Z., LI, W.-T., YE, X.-D., PENG, W.-J. \& XIAO, X.-S. 2014. Utility of diffusion-weighted imaging to assess hepatocellular carcinoma viability following transarterial chemoembolization. Oncology letters, 8, 831-836.

23.LU, T. L., BECCE, F., BIZE, P., DENYS, A., MEULI, R. \& SCHMIDT, S. 2012. Assessment of liver tumor response by high-field (3 T) MRI after radiofrequency ablation: short- and mid-term evolution of diffusion parameters within the ablation zone. Eur J Radiol, 81, e944-50.

24. MANNELLI, L., KIM, S., HAJDU, C. H., BABB, J. S., CLARK, T. W. I. \& TAOULI, B. 2009. Assessment of Tumor Necrosis of Hepatocellular Carcinoma After Chemoembolization: DiffusionWeighted and Contrast-Enhanced MRI With Histopathologic Correlation of the Explanted Liver. American Journal of Roentgenology, 193, 10441052.

25.WANG, H., ZOU, Q. \& LIU, P.-F. J. C. J. O. M. I. T. 2011. Evaluation on the therapeutic effect of transcatheter arterial chemoembolization in hepatocellular carcinoma with DWI and dynamic contrast-enhanced MR imaging [J]. 4.

26. GLUSKIN, J. S., CHEGAI, F., MONTI, S., SQUILLACI, E. \& MANNELLI, L. 2016. Hepatocellular Carcinoma and Diffusion-Weighted MRI: Detection and Evaluation of Treatment Response. Journal of Cancer, 7, 1565-1570.

To cite this article: Hamed A. Morsi, Medhat M. Refaat, Osama T. Galal. The Role of Diffusion Weighted MRI in The Assessment of Post Ablation HCC Viability. BMFJ. 2020;37(2):326-339. DOI: 10.21608/bmfj.2020.15390.1028 